University of Warwick institutional repository

This paper is made available online in accordance with

publisher policies. Please scroll down to view the document

itself. Please refer to the repository record for this item and our

policy information available from the repository home page for further information.

To see the final version of this paper please visit the publisher's website. Access to the published version may require a subscription.

Author(s): R. Noble, T. R. Fermor,S. Lincoln A. Dobrovin-Pennington, C. Evered and A. Mead

Article Title: Primordia initiation of mushroom (Agaricus bisporus) strains on axenic casing materials

Year of publication: 2003

Link to published version: http://dx.doi.org/10.2307/3761938

Publisher statement: none 


\section{Primordia initiation of mushroom (Agaricus bisporus) strains on axenic casing materials}

R. Noble ${ }^{1}$

T. R. Fermor

S. Lincoln

A. Dobrovin-Pennington

C. Evered

A. Mead

Horticulture Research International, Wellesbourne, Warwick, CV35 9EF, United Kingdom

\section{R. Li}

Department of Agriculture, Yunnan Agriculture University, Kunming 650201, China

\begin{abstract}
The mushroom (Agaricus bisporus) has a requirement for a "casing layer" that has specific physical, chemical and microbiological properties which stimulate and promote the initiation of primordia. Some of these primordia then may develop further into sporophores, involving differentiation of tissue. Wild and commercial strains of A. bisporus were cultured in axenic and nonaxenic microcosms, using a rye grain substrate covered by a range of organic and inorganic casing materials. In axenic culture, A. bisporus (commercial strain A15) was capable of producing primordia and mature sporophores on charcoal (wood and activated), anthracite coal, lignite and zeolite, but not on bark, coir, peat, rockwool, silica or vermiculite. Of six strains tested, only the developmental variant mutant, B430, produced rudimentary primordia on axenic peat-based casing material. However, none of these rudimentary primordia developed differentiated tissues or beyond 4 $\mathrm{mm}$ diameter, either on axenic casing material in the microcosms or in larger-scale culture. In larger-scale, nonaxenic culture, strain B430 produced severely malformed but mature sporophores in similar numbers to those of other strains. Typically, 3-6\% of primordia developed into mature sporophores, but significant differences in this proportion, as well as in the numbers of primordia produced, were recorded between 12 A. bisporus strains.
\end{abstract}

Key words: aggregate, hypha, mycelium, primordium, Pseudomonas putida, sporophore

Accepted for publication December 23, 2002.

${ }^{1}$ Corresponding author. E-mail: ralph.noble@hri.ac.uk

\section{INTRODUCTION}

The initiation of sporophores of the mushroom Agaricus bisporus (Lange) Sing. begins with the aggregation of mycelium into thick strands or hyphal cords (Umar and van Griensven 1997). This initiation is followed by the formation of primordia, defined by Wood (1976) as structures greater than $1 \mathrm{~mm}$ diameter composed of a dense hyphal mesh with a smooth surface and visibly distinct from strands or knots of hyphae. Flegg (1979) referred to the latter as "mycelial aggregates". In addition to a nutritional substrate, e.g., compost (Noble et al 1998), most A. bisporus strains have a requirement for a separate "casing layer" that has specific physical, chemical and microbiological properties which stimulate and promote the initiation of primordia (Eger 1961, Flegg and Wood 1985). Primordia are formed after mycelial colonization of the nutritional substrate and casing layer. Development of primordia is stimulated by a reduction in temperature and $\mathrm{CO}_{2}$ (Flegg and Wood 1985) and by the presence of bacteria in the casing layer, of which Pseudomonas putida (Trevisan) Migula is regarded as most significant (Hayes et al 1969, Park and Agnihotri 1969). Long and Jacobs (1974) showed that activated charcoal could replace the function of stimulatory bacteria in the casing layer, possibly by adsorbing compounds that were inhibitory to initiation (Wood and Blight 1983). After initiation, some primordia may continue to develop in size and by differentiation of tissues into sporophores (Wood 1979).

Strains of A. bisporus have been found to vary markedly in their ability to form primordia axenically on malt-extract agar (MEA). Using 12 strains of commercial origin, Wood $(1976,1979)$ found that such primordia were formed asynchronously. Wannet et al (1999) found two wild strains from the Agaricus Recovery Programme (ARP) collection (Sylvan Spawn Laboratory Inc., West Hills Industrial Park, Kittaning, Pennsylvania), 116 and 155.8, which produced primordia after mycelial colonization of MEA, usually at the edge of the plate. Except in rare cases, none of the above strains produced sporophores in the absence of a casing layer, and none produced primordia on defined-agar media. Elliott and Wood (1978) isolated two developmental variant, mutant $A$. bisporus strains (B430 and B431) that produced primordia 


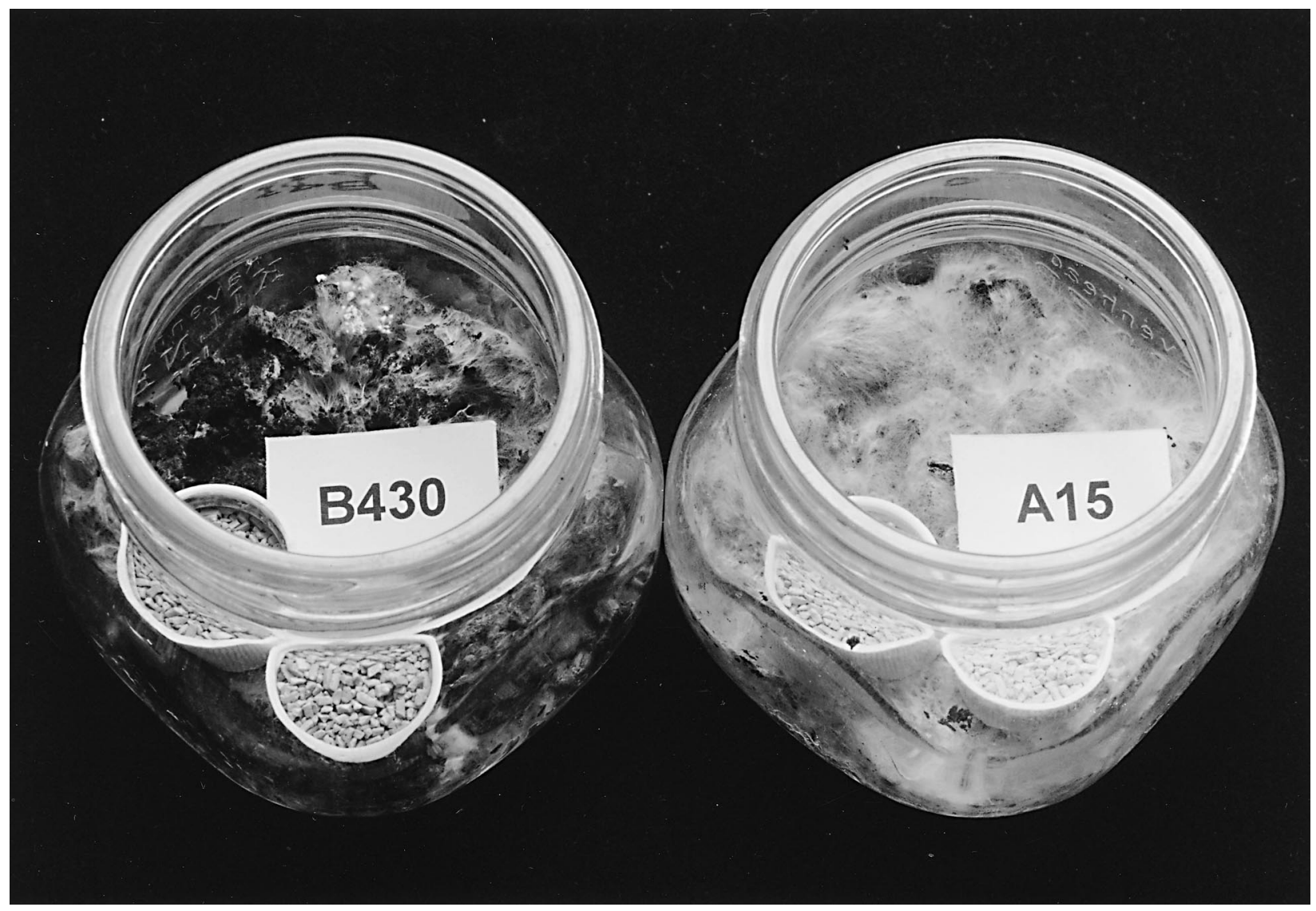

FIG. 1. Kilner jar microcosm, A. bisporus strains B430 and A15.

synchronously throughout mycelial growth on defined-minimal media but were not shown to produce mature sporophores.

The aims of the current work were to determine if: (i) axenic casing materials other than activated charcoal could stimulate initiation; (ii) the mutant strain B430 and other wild A. bisporus isolates could initiate primordia and develop sporophores on an axenic casing layer; (iii) primordia and sporophores of the above strains develop normally under nonaxenic conditions, compared with commercial A. bisporus strains.

\section{MATERIALS AND METHODS}

Axenic microcosm tests.-A microcosm $(500 \mathrm{~mL}$, Kilner jar, Ravenhead Glass Ltd, St. Helens, Lancashire, United Kingdom) culture system, modified from Rainey (1989), was used to examine growth in axenic casing materials (FIG. 1). The microcosms were filled with a $10 \mathrm{~mm}$ layer $(30 \mathrm{~g})$ of sterile rye grain "spawn" (Elliott 1985), which served as a nutritional substrate, colonized with the appropriate A. bisporus strain. This substrate was covered with $60 \mathrm{~g}$ (about 17 mm layer, surface area $64 \mathrm{~cm}^{2}$ ) of casing material, consisting of a mixture of black peat and $\mathrm{CaCO}_{3}(4: 1 \mathrm{v} / \mathrm{v})$ or other materials. Gamma irradiation (Technical Service Consul- tants Ltd, Heywood, Lancashire, United Kingdom) was used to produce axenic casing material, to avoid physical and chemical changes caused by autoclaving. The microcosms were incubated at $25 \mathrm{C}$ until mycelium had started to colonize the surface of the casing layer, normally 3-5 d after the jars were filled. To promote conditions in the microcosms for initiation to occur, the $\mathrm{CO}_{2}$ concentration was reduced from about $0.4 \% \mathrm{v} / \mathrm{v}$ to $0.08-0.12 \% \mathrm{v} / \mathrm{v}$ by placing two sterile plastic caps, each containing $5 \mathrm{~g}$ self-indicating, 1-2.5 mm mesh soda lime granules, in each microcosm. The microcosms then were transferred to a $16 \mathrm{C}$ cabinet; the soda lime was replaced when necessary, and the casing layer irrigated with up to $15 \mathrm{~mL}$ sterile water after about 14 $\mathrm{d}$ to maintain a matric potential of -1 to $-2 \mathrm{kPa}$ (Noble et al 1999). The matric potential, $\mathrm{pH}$ and electrical conductivity of casing materials were determined according to Noble et al (1999).

The numbers of primordia $\geq 1 \mathrm{~mm}$ diameter were recorded $21 \mathrm{~d}$ after transfer to $16 \mathrm{C}$; axenic or nonaxenic conditions were maintained in the microcosms for a further $21 \mathrm{~d}$ to determine if primordia developed into mature sporophores, i.e., Stage 5 (Hammond and Nichols 1976) pileus with broken veil and gills exposed.

Initiation on axenic and nonaxenic casing materials. The types and sources of the 12 organic and inorganic casing materials used are shown in TABLE I. Peat and lignite were too acidic for mycelial growth; $\mathrm{CaCO}_{3}$, therefore, was added 


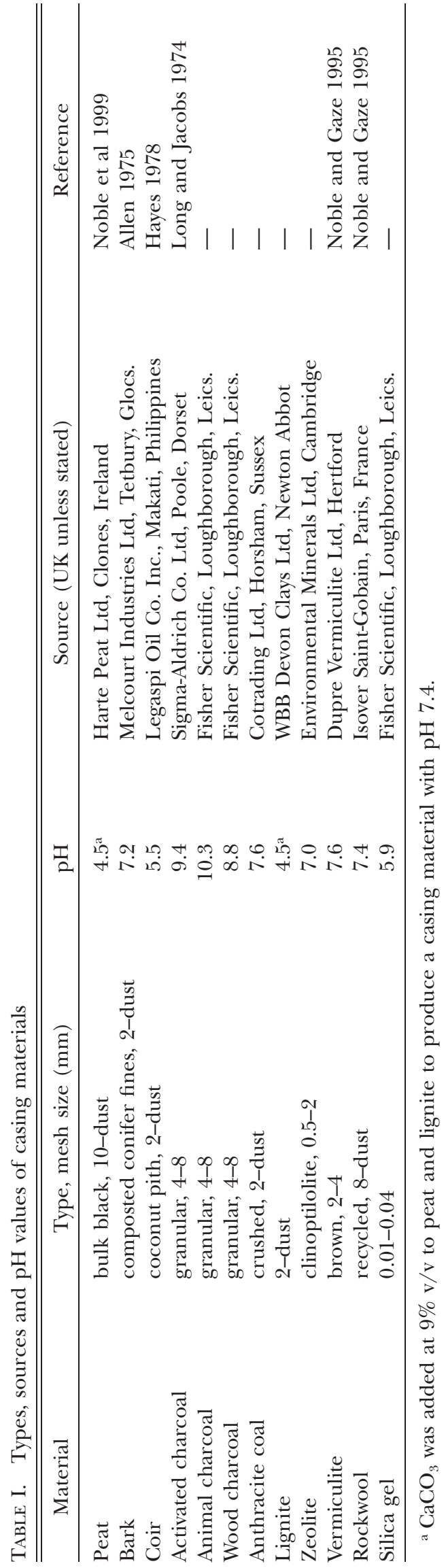

at $9 \% \mathrm{v} / \mathrm{v}$ to achieve a $\mathrm{pH}$ of 7.4 (TABLE I). The commercial white hybrid A. bisporus strain Sylvan A15 (Sylvan Spawn Ltd, Peterborough, United Kingdom) was used. Each of six replicates consisted of four blocks, each containing three pairs of jars. Each pair of jars contained the same casing material, one of each pair randomly selected to contain axenic material and other nonaxenic material. Casing materials were allocated to blocks within replicates following an alpha design, such that pairs of casing materials appeared within a block no more than twice. This allocation ensured that the precision of comparisons between pairs of casing materials was as equal as possible across all pairs.

Data from this experiment were analyzed with the restricted-maximum likelihood (REML) approach (Thompson and Welham 2000), to allow for proper adjustment for differences between blocks within replicates. This approach also enabled comparisons between treatments that allowed for the variation in the precision of different paired comparisons.

Axenic and nonaxenic initiation of A. bisporus strains. These A. bisporus strains were used: commercial strain A15, UK wild strains 96-4, 97-3 (HRI Culture Collection, Wellesbourne, Warwick, United Kingdom), American wild strains JB10, JB157 (deposited as ARP116, ARP155, Sylvan Spawn Laboratory Inc.) and the developmental variant B430 (HRI Culture Collection). Strains ARP116 and ARP155 are var. burnettii with mainly tetrasporic basidia (Callac et al 1993); all other strains are var. bisporus with mainly bisporic basidia. This experiment was arranged as a split-plot design with six replicate blocks that each contained six pairs of jars. Each pair of jars contained the same strain, one with axenic and the other with nonaxenic casing material. Data from this experiment were analyzed using analysis of variance.

Flask culture.-Composted substrate (Noble et al 1998) (400 g) was filled to a depth of $80 \mathrm{~mm}$ in $2 \mathrm{~L}$ "Quickfit" multiadapter flasks (Fisher Scientific, Loughborough, United Kingdom) and covered with $180 \mathrm{~g}$ of the above peat and $\mathrm{CaCO}_{3}$ casing material to a depth of $28 \mathrm{~mm}$ (surface area $113 \mathrm{~cm}^{2}$ ). After autoclaving (axenic flasks only), the substrate was inoculated with two $5 \mathrm{~mm}$ plugs of A. bisporus mycelium grown on MEA, through holes made in the casing layer. The flasks were sealed with bacterial air vents and kept at $25 \mathrm{C}$ until mycelium became visible at the surface of the casing material, which then was watered with $50 \mathrm{~mL}$ sterile water. The flasks then were transferred to a room at $18 \mathrm{C}$ and connected to a filtered air flow of $15 \mathrm{~L} \mathrm{~h}^{-1}$ to maintain a $\mathrm{CO}_{2}$ concentration of $0.06-0.12 \% \mathrm{v} / \mathrm{v}$. Primordia and sporophores were recorded in the same way as for culture in microcosms.

Initiation of A. bisporus strains in axenic and nonaxenic flask culture.-These A. bisporus strains were used: commercial strain A15, UK wild strain 97-3, and the strain B430. Two replicate axenic and nonaxenic flasks were prepared with each strain, arranged in a randomized block design.

Larger-scale nonaxenic culture.-A. bisporus strains were cultured with polypropylene trays $(60 \times 40 \times 18$ [deep] $\mathrm{cm})$ in a controlled-environment room, with cultural conditions as described in Noble et al (1999). Each tray contained 9 
$\mathrm{kg}$ of the above composted substrate colonized with A. bisporus strains after inoculation with $1 \% \mathrm{w} / \mathrm{w}$ rye grain spawn as mentioned above. The substrate was covered with a 28 mm deep casing layer, which consisted of a 4:1 v/v mixture of black peat and $\mathrm{CaCO}_{3}$ (Noble et al 1999).

Initiation of A. bisporus strains in larger-scale nonaxenic culture.-These A. bisporus strains were used: commercial white hybrid strains 2100 (Amycel Ltd, Burton, Staffordshire, United Kingdom) and A15, UK wild strains 96-4, 97-2, 97-3, JFB II, JFB III (HRI Culture Collection), AMA4 (deposited as ARP174, Sylvan Spawn Laboratory Inc.) and American wild strains ARP116, ARP130, ARP155 (Sylvan Spawn Laboratory Inc.) and the strain B430. Strains ARP130 and ARP174 are var. burnettii and var. bisporus respectively. Four replicate trays of each strain were prepared; two of the trays were used for recording the population of primordia and sporophores, while the casing layer in the other two trays was not disturbed and only the number of sporophores was recorded. Each tray was divided into a 3 $\times 5$ grid, each square measuring $10 \times 10 \mathrm{~cm}$. At each recording date, the casing layer in a randomly selected square was removed carefully so as not to disturb adjacent squares. The full depth of casing layer then was examined to record the number of primordia. After recording, all Stage 5 sporophores (Hammond and Nichols 1976) were removed and the disturbed casing layer sample was replaced over the compost in the square on the tray. Individual squares in the grid were examined once. Primordia and sporophores were recorded at $2 \mathrm{~d}$ intervals for $26 \mathrm{~d}$ after the first primordia were visible. The numbers of primordia and sporophores were recorded by examination of destructively sampled casing layer and recording the number of: (i) live primordia 1-3 mm diameter (small primordia) (Wood 1976, Flegg 1979); (ii) live primordia $>3 \mathrm{~mm}$ diameter (large primordia); (iii) dead primordia $\geq 1 \mathrm{~mm}$ diameter; (iv) sporophores that had reached Stage 5 (Hammond and Nichols 1976). A small number of primordia that were attached to the base of sporophores were recorded in the above categories. The numbers of primordia in the recording areas were plotted against time. Estimates of primordia numbers on days between the recording dates were obtained by cubic interpolation between the observed points. Where this cubic interpolation gave negative estimates, values were reset to zero. A measure of the total production and survival of primordia was obtained by summing the daily counts (both observed and interpolated), giving an approximate area under the interpolated curve for each strain, referred to as the integral number of primordia. These parameters of growth curves were analyzed: (a) the area under the curve, i.e., the integral numbers of primordia in categories (i) to (iii) with time; (b) the peak value of primordial numbers in categories (i) to (iii).

Core (20 $\mathrm{mm}$ diameter) profiles of the casing layer also were examined with either a binocular microscope $(\times 10)$ or scanning electron microscope (SEM) $(\times 35-\times 100)$ after gold coating of frozen hydrated samples of casing material, with mycelium and primordia attached.

Two replicates of the 12 strains were arranged following a latinized row-column alpha design. Each replicate was ar- ranged in a single layer of trays (three trays wide by eight trays deep), each strain being applied to a pair of adjacent trays. Within each pair of trays, one was left undisturbed, while the casing of the other was sampled on occasions during crop development (these treatments applied at a subplot level). The design ensured that each strain only appeared at most once in each of four blocks of trays along the length of the experiment and that the precision of comparisons between pairs of strains was as equal as possible across all pairs.

Data from this experiment first were analyzed using the REML approach to allow proper adjustment for differences between rows and columns within replicates, but with little evidence of any positional variation, a simpler analysis of variance was used.

Measurement of bacterial numbers in casing materials.-In all the experiments, bacteria were isolated from casing materials on nutrient and Pseudomonas isolation agars (PIA) (Difco Laboratories, Detroit, Michigan) to determine the total bacterial populations as colony forming units per g dry weight casing material $\left(\mathrm{cfu} \mathrm{g}^{-1}\right)$ and to estimate the proportion that were Pseudomonas spp. An estimate of the proportion of Pseudomonas spp. that were P. putida isolates was obtained with these tests (Stanier et al 1966, Lelliott and Stead 1987) on 30 cfus from the PIA isolation: (i) fluorescence under UV light on Pseudomonas Agar F (PAF) (Merck Ltd., Poole, Dorset, United Kingdom); (ii) inability to hydrolyze gelatin; (iii) arginine dihydrolaze test positive. Results from these tests on Pseudomonas spp. isolates previously were found to correspond to characterization by ribotyping (Fermor et al 2000).

Bacterial and primordial populations showed evidence of a mean-variance relationship. These populations respectively were subjected to a logarithmic or square root transformation before analysis. All differences in the results section were significant at $P<0.05$, or if stated, $P<0.01$ or 0.001 .

\section{RESULTS}

Measurement of primordia.-Both binocular light microscopy and SEM observations showed that the earliest distinguishable initials were at least $0.5 \mathrm{~mm}$ in diameter. Mycelial knots or aggregates smaller than this consisted mainly of a disorientated mass of hyphae (strains A15 and B430). These could not be distinguished easily from the vegetative hyphae and hyphal "cords" (as observed by Umar and van Griensven 1997). Visual observation of primordia 0.5 $\mathrm{mm}$ or greater in diameter, in a larger casing material sample, therefore was a more reliable method for measuring the occurrence and amount of primordia. The development of primordia and sporophores was slower in the microcosm tests than in the larger-scale culture due to the lower temperature $(16 \mathrm{C}$ compared with 18 C) (Flegg 1979).

Primordia initiation on axenic casing materials.-The casing material in microcosms in which initiation did 


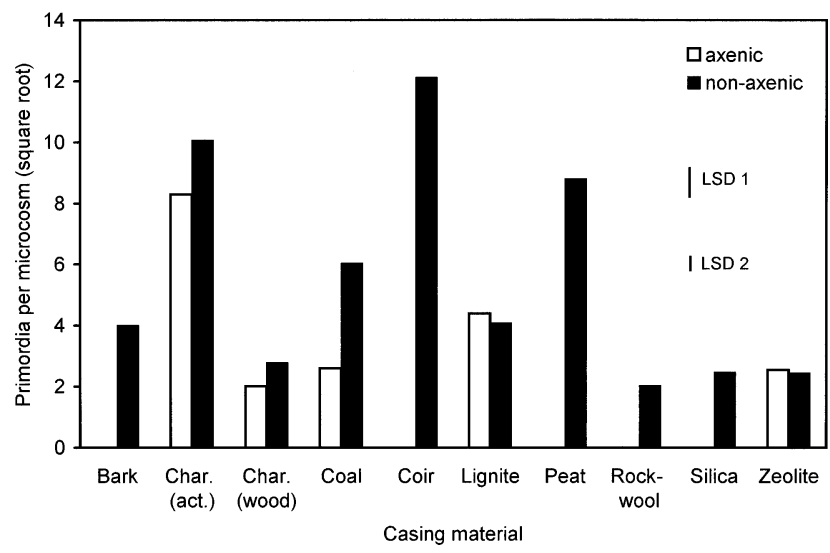

FIG. 2. Numbers of primordia $\geq 1 \mathrm{~mm}$ diameter (square root transformation) produced in different axenic and nonaxenic casing materials. No primordia formed on vermiculite or on animal charcoal. LSDs are at $P=0.05$. LSD $1(60$ df) is for comparing casing materials of the same sterility treatment; LSD 2 (159 df) is for comparing sterility treatments of the same casing material.

not occur became overgrown with mycelium i.e., stroma (Fletcher et al 1986), except in animal charcoal, where mycelial growth was poor. This might have been due to the high $\mathrm{pH}$ value of this casing material (TABLE I). After initiation on the casing materials, mycelial growth declined or stopped.

No primordia formed on axenic bark, coir, peat, rockwool, silica gel or vermiculite, or on animal charcoal (FIG. 2). Primordia formed on axenic and nonaxenic charcoal (wood and activated), coal, lignite and zeolite. Of the axenic materials, most primordia formed on activated charcoal, and of the nonaxenic materials, more primordia formed on coir, activated charcoal and peat than on the other materials $(P<$ $0.01)$. In axenic and nonaxenic microcosm treatments in which primordia were recorded, 1-2 primordia developed into mature sporophores. Two primordia formed in one of the six replicate microcosms of the nonaxenic vermiculite treatment, and one of these developed into a mature sporophore.

In the nonaxenic casing materials at the end of the experiment, bacterial numbers were lowest in the lignite treatment $\left(15 \mathrm{cfu} \mathrm{g}^{-1}\right)$ and greater in wood and animal charcoal $\left(3 \times 10^{8}-4 \times 10^{8} \mathrm{cfu} \mathrm{g}^{-1}\right)$ than in the other materials $\left(10^{5}-7 \times 10^{7} \mathrm{cfu} \mathrm{g}^{-1}\right)(P<0.01)$. There was no correlation between the numbers of primordia and the numbers $\left(\mathrm{cfu} \mathrm{g}^{-1}\right)$ of total bacteria or Pseudomonas spp. in different casing materials. In peat casing, $38 \%$ of the total bacterial population were estimated as being Pseudomonas spp. and 13\% produced classical $P$. putida reactions, according to the tests of Stanier et al (1966). In zeolite, bark, charcoal, coal and lignite casing materials, $18-62 \%$ of the bacteria were estimated to be Pseudomonas spp. but

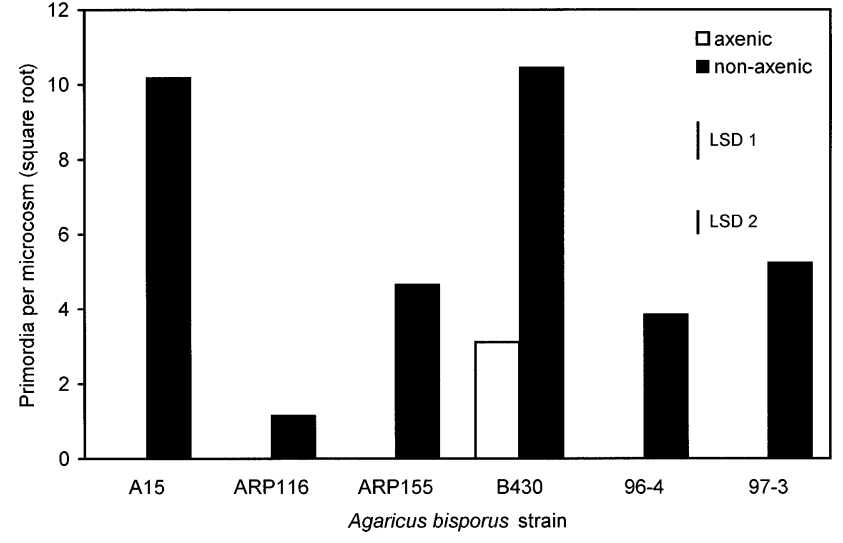

FIG. 3. Numbers of primordia $\geq 1 \mathrm{~mm}$ diameter (square root transformation), produced by different $A$. bisporus strains on axenic and nonaxenic peat-based casing material. LSDs are at $P=0.05$. LSD 1 ( $25 \mathrm{df})$ is for comparing strains of the same sterility treatment; LSD 2 (30 df) is for comparing sterility treatments of the same strain

none of the isolated bacteria produced classical $P$. putida reactions. In coir and vermiculite casing materials, none of the isolated bacteria grew on PIA and therefore were unlikely to be Pseudomonas spp. No bacteria were detected in the axenic microcosms at the end of the experiment.

The electrical conductivities of activated charcoal, animal charcoal, coir and lignite (range 922 to 1486 $\mu \mathrm{S})$ were higher than those of the other casing materials (range 58 to $452 \mu \mathrm{S}$ ). Coir and silica gel had lower $\mathrm{pH}$ values and the charcoal sources had higher $\mathrm{pH}$ values than the other casing materials (TABLE I). However, there were no relationships between casing electrical conductivity or $\mathrm{pH}$ and the initiation of primordia.

Axenic and nonaxenic initiation of $\mathrm{A}$. bisporus strains.-B430 was the only strain to produce primordia on axenic peat-based casing material, but here the number produced was less than on nonaxenic material $(P<0.001$, Figs. 1 and 3$)$. The other strains produced only vegetative mycelium in axenic peat-based casing material (Figs. 1 and 3). The rudimentary primordia of $\mathrm{B} 430$ were similar to those shown by Elliott and Wood (1978). Between 3-5 of these primordia in each axenic or nonaxenic microcosm reached a diameter of $4 \mathrm{~mm}$, but none of the primordia formed differentiated tissues associated with developing sporophores (Wood 1979). For the other strains in nonaxenic microcosms, 1-2 primordia developed into mature sporophores. Strains A15 and $\mathrm{B} 430$ produced more primordia than the other strains in nonaxenic casing, whereas strain ARP116 produced the fewest $(P<0.01$, Fig. 3).

Bacterial populations at the end of the experiment 
TABLE II. Numbers of primordia (square root and back-transformed values) and sporophores produced by A. bisporus strains in axenic and nonaxenic flask cultures. Each value is the mean of two flasks

\begin{tabular}{|c|c|c|c|c|}
\hline \multirow[b]{2}{*}{ Strain } & \multirow[b]{2}{*}{ Culture } & \multicolumn{2}{|c|}{ Number of primordia $\geq 1 \mathrm{~mm}$} & \multirow[b]{2}{*}{ Sporophores (stage 5) } \\
\hline & & Mean & Square root & \\
\hline \multirow[t]{2}{*}{ A15 } & axenic & 0 & $(0.0)$ & 0 \\
\hline & nonaxenic & 161 & $(12.6)$ & 7 \\
\hline \multirow[t]{2}{*}{ B430 } & axenic & 24 & $(4.9)$ & 0 \\
\hline & nonaxenic & 178 & $(13.3)$ & 5 \\
\hline \multirow[t]{2}{*}{$97-3$} & axenic & 0 & $(0.0)$ & 0 \\
\hline & nonaxenic & 48 & $(6.9)$ & 7 \\
\hline $\operatorname{LSD}(P=0.05,6 \mathrm{df})$ & & & $(4.43)$ & 4.7 \\
\hline
\end{tabular}

$\left(5 \times 10^{5}-2 \times 10^{6} \mathrm{cfu} \mathrm{g}^{-1}\right)$ were not affected by the A. bisporus strains in the nonaxenic microcosms. Of these populations, $60 \%$ were estimated to be Pseudomonas spp. and $22 \%$ were estimated to be P. putida, according to the above tests. No bacteria were detected in the axenic microcosms at the end of the experiment.

Initiation of $\mathrm{A}$. bisporus strains in axenic and nonaxenic flask culture.-As in the previous experiment, B430 was the only strain to produce primordia on axenic peat-based casing material, and again none of these primordia grew beyond a diameter of $4 \mathrm{~mm}$ and the number produced was less than on nonaxenic material (TABLE II). The other two A. bisporus strains produced only vegetative mycelium in axenic peat-based casing material, but all three strains produced mature sporophores in the nonaxenic flasks.

At the end of the experiment, bacterial populations in the nonaxenic flasks were $6.6 \times 10^{6}-9.4 \times$ $10^{6} \mathrm{cfu} \mathrm{g}^{-1}$ and no bacteria were detected in the axenic flasks.

Larger-scale nonaxenic culture of A. bisporus strains.The first primordia were recorded 8-9 d (16 d for strain ARP155) after the casing material was applied, and the first sporophores attained Stage 5 development (Hammond and Nichols 1976) after 13-18 d (22 d for ARP155). A. bisporus (var. bisporus) strains had $80-98 \%$ bisporic basidia (50 observed basidia) and A. bisporus (var. burnettii) strains had 73-100\% tetrasporic basidia. This result agrees with Callac et al (1993), who observed 17-100\% bisporic basidia and $0-24 \%$ tetrasporic basidia for var. bisporus and 0 $8 \%$ bisporic and 54-100\% tetrasporic basidia for var. burnettii. Sporophores of all the wild strains had brown caps, with ARP116 and ARP130 being darker than JFB II, JFB III; the caps of 96-4, 97-2 and 97-3 were pale brown. Strain B430 produced severely distorted sporophores with gill and spore tissue on the pileus surface, similar to "rosecomb" described by
Fletcher et al (1986), and split stipes (FIG. 4). However, gill tissue was normal, producing viable spores.

Most primordia were formed close to the surface of the casing layer; very few primordia were formed in the lower $20 \mathrm{~mm}$ of the casing layer. Strains 2100 , 97-3 and ARP130 produced more small (1-3 mm) and total primordia than the other strains, both in terms of the peak and integral numbers of primordia (TABle III). Strains JFBII, ARP116, ARP155 and ARP174 produced the smallest integral numbers of primordia and the first three of these strains also produced the smallest peak numbers in primordia (TABLE III). Strain ARP130 produced the most large primordia $(>3 \mathrm{~mm})$ and Strain ARP174 the fewest. Strain 97-3 produced the most dead primordia, and strains 97-2, ARP155 and ARP174 the fewest (TABLE III).

Differences in the timing of production of primordia by $A$. bisporus strains were observed. The peak numbers of small, large and total primordia of strains 2100, 96-4, 97-2, 97-3, ARP116, ARP130, B430, JFBII and JFBIII occurred at or before the first "flush" of sporophores. With strains A15, ARP155 and ARP174, the peak number of small, large and total primordia occurred after the first flush of sporophores. The timing of production of primordia and sporophores of strains A15, B430, 97-3 and 96-4 is shown in FIG. 5 . With all strains, there was an increase in the numbers of these categories of primordia before each flush of sporophores, and there was a marked increase in the number of dead primordia between days 14 and 35 after the first recording of primordia (FIG. 5). The numbers of dead initials probably were underestimated because they discolored and decayed rapidly before being counted.

The integral number of small primordia produced by a strain closely correlated with the total integral number of primordia and integral number of dead primordia it produced $\left(r^{2}=0.98\right.$ and $0.71 ; P<$ 0.001). Most strains produced 198-240 mature spo- 


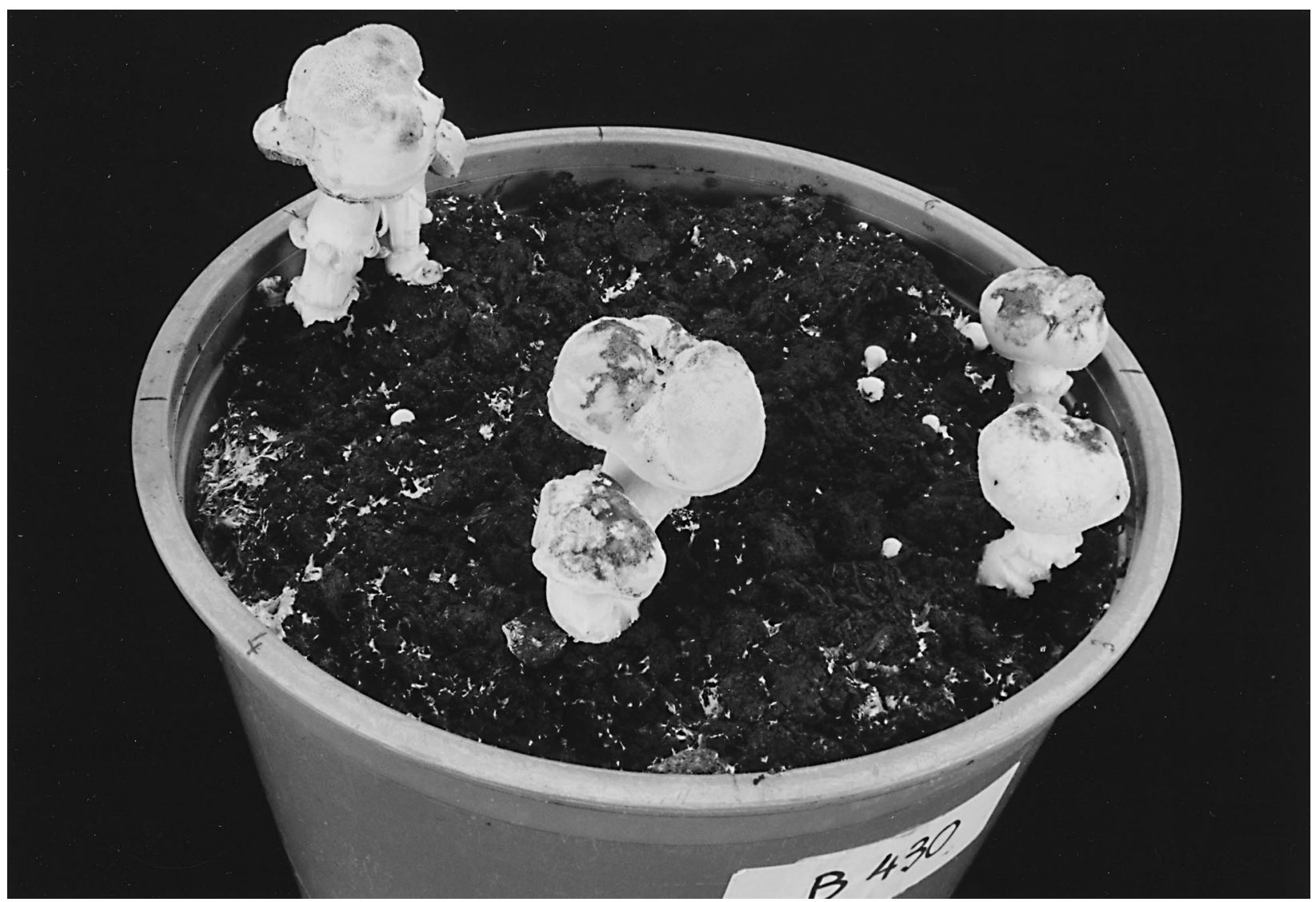

FIG. 4. A. bisporus strain B430 in nonaxenic culture.

rophores per tray. Strain 97-3 produced more, and strains ARP130, ARP155 and JFBII produced fewer mature sporophores per tray (TABLE III). There were no correlations between the numbers of sporophores and primordia for different strains or between num- bers of primordia produced by the six A. bisporus strains in microcosms and the same strains in largerscale culture.

Bacterial populations in the casing material on the trays were similar to those recorded on peat-based

TABLE III. Peak and integral numbers of primordia and numbers of sporophores for different A. bisporus strains. Means of peak primordia numbers are back-transformed values. Numbers are per $0.1 \mathrm{~m}^{2}$ of tray area

\begin{tabular}{|c|c|c|c|c|c|c|c|}
\hline \multirow[b]{3}{*}{ Strain } & \multicolumn{2}{|c|}{ Peak primordia } & \multirow[b]{3}{*}{ Sporophores } & \multirow{2}{*}{\multicolumn{4}{|c|}{ Integral numbers of primordia }} \\
\hline & & Square & & & & & \\
\hline & Mean & root & & $1-3 \mathrm{~mm}$ & $>3 \mathrm{~mm}$ & Dead & Total \\
\hline Sylvan A15 & 367 & $(19.1)$ & 14 & 4096 & 673 & 692 & 5451 \\
\hline Amycel 2100 & 404 & $(20.1)$ & 13 & 5080 & 496 & 787 & 6362 \\
\hline ARP116 & 149 & $(12.2)$ & 16 & 1925 & 209 & 282 & 2414 \\
\hline ARP130 & 451 & $(21.2)$ & 1 & 4654 & 1755 & 253 & 6657 \\
\hline ARP155 & 168 & $(12.9)$ & 2 & 1975 & 234 & 58 & 2245 \\
\hline ARP174 & 254 & $(15.6)$ & 16 & 1373 & 83 & 18 & 1466 \\
\hline B430 & 215 & $(14.7)$ & 13 & 2682 & 368 & 608 & 3653 \\
\hline JFBII & 260 & $(16.1)$ & 7 & 3329 & 369 & 639 & 4335 \\
\hline JFBIII & 89 & $(9.4)$ & 14 & 1990 & 724 & 223 & 2935 \\
\hline $96-4$ & 358 & $(18.8)$ & 16 & 3141 & 568 & 625 & 4324 \\
\hline $97-2$ & 240 & (15.4) & 14 & 2691 & 429 & 132 & 3251 \\
\hline $97-3$ & 420 & $(20.5)$ & 20 & 5838 & 810 & 1360 & 7994 \\
\hline $\operatorname{LSD}(P=0.05,11 \mathrm{df})$ & & $(4.05)$ & 2.9 & 2014.5 & 251.0 & 258.1 & 2101.4 \\
\hline
\end{tabular}



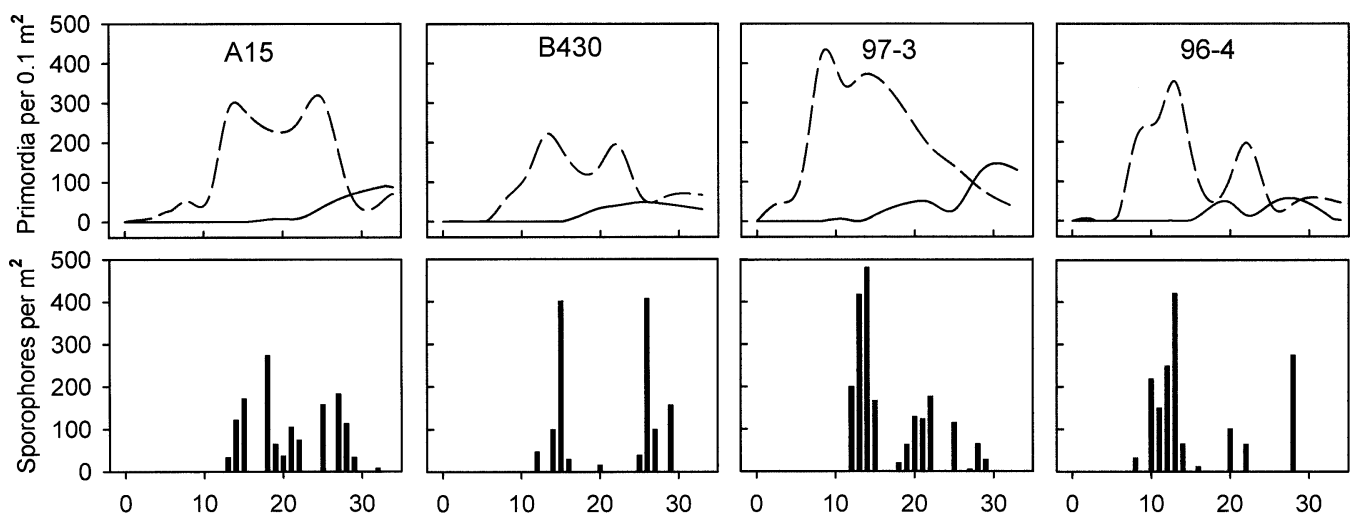

Time, d

FIG. 5. Development of primordia and sporophores of four A. bisporus strains. Broken line: live primordia, solid line: dead primordia. The method used for curve fitting is described in the text. Days are counted from transfer to $18 \mathrm{C}, 5 \mathrm{~d}$ after applying casing material.

materials in the microcosms and flasks. They were not affected by the $A$. bisporus strains $\left(10^{5}-10^{7} \mathrm{cfu}\right.$ $\mathrm{g}^{-1}$ ), and $49 \%$ of the bacterial populations were estimated to be Pseudomonas spp. and $20 \%$ were estimated to be $P$. putida, according to the above tests.

\section{DISCUSSION}

Primordia initiation on different casing materials.The results found here agree with Visscher (1979), who found no fruiting of A. bisporus on sterile peat, rockwool or organic wastes (or on sand, brown coal, glasswool, glass beads and chopped bricks), but initiation occurred on these materials if they were treated with an aqueous-filtered extract of normal casing material. As here, Long and Jacobs (1974) and Wood and Blight (1983) found that initiation occurred on axenic activated charcoal, although our experiments also showed that other carbonized materials (wood charcoal, coal and lignite), as well as zeolite, could stimulate initiation in axenic culture. The observation made here-of mycelial growth declining or stopping after initiation on different casing materials-also was made by Eger (1962) after the introduction of stimulatory bacteria into the casing layer of sterile cultures of $A$. bisporus.

The results here indicate that different casing materials support different populations of bacteria, although these were not related to the numbers of initials formed. The proportions of fluorescent Pseudomonas spp. found in peat casing (16-56\%) correspond to those of Miller et al (1995), who found that they were $14-41 \%$ of the total bacteria present. Hayes and Nair (1974) found that the proportion of Pseudomonas spp. increased from $34 \%$ of the total bacteria present at the time peat casing was applied to $95 \%$ of the total bacteria at the end of a mushroom crop. Although coir and vermiculite did not appear to support the growth of Pseudomonas spp., other genera of bacteria, Bacillus and Alcaligenes, have been shown to stimulate initiation of $A$. bisporus (Park and Agnihotri 1969, Fermor et al 2000).

Previous attempts to isolate the putative inhibitors to initiation from activated charcoal have been confounded by the large number of compounds adsorbed and identified (Grove 1981, Wood and Blight 1983). Of these, 1-octen-3-ol was found to inhibit primordial formation in plate culture. Here, more primordia were formed on axenic activated charcoal than on other axenic materials; this might be due to the relatively greater adsorption action of the material (Long and Jacobs 1974). Chemical analysis by gas chromatography-mass spectrometry of adsorbent, stimulatory and nonstimulatory casing materials might identify differences in compounds present. Initiation on zeolite might provide the opportunity to selectively adsorb putative fruiting inhibitors, using a range of synthetic zeolites with different adsorption characteristics (Eitel 1966).

Primordia initiation of different A. bisporus strains.Tschierpe (1983) and Fritsche and Sonnenberg (1988) recorded differences in the number of primordia produced by different $A$. bisporus strains under similar cultural conditions, and Flegg (1979) found that this proportion could be altered by temperature. Here, an estimate of the proportion of primordia that developed into sporophores could be obtained by dividing the peak number of total primordia (including primordia that developed into sporophores before the peak) by the numbers of sporophores that developed (TABLE II, FIG. 5). These proportions are overestimates because primordia that developed between the peak value and Day 35 are 
not included and the number of dead initials might be underestimates as previously mentioned. In most strains, $2.7-6.1 \%$ of primordia developed into sporophores. In strains ARP116 and JFBIII, these figures were higher (10.4 and 15.6\%), and in strains ARP130 and ARP155 they were lower (0.2 and 1.2\%). The proportions found here correspond to those of Flegg (1979), who found that $3.2 \%$ of primordia of the strain D649 developed into sporophores at a cropping temperature of $16 \mathrm{C}$. He also suggested that the sporophores, which develop during a period of several weeks, arise from mycelial aggregates formed during the period immediately after casing is applied to the start of the first flush. This observation agrees with the results in this work, although in some strains (97-3 and ARP174) significant numbers of new primordia developed after the first flush of sporophores. Wannet et al (1999) found that all hyphal knots were formed before the first period of aggregate development on MEA. At each period of aggregate release or flush, about $2-5 \%$ of these knots developed synchronously into aggregates.

Strain ARP116 did not produce primordia on an axenic casing layer, although Wannet et al (1999) found that it produced primordia on axenic MEA. In nonaxenic culture, the production of primordia and sporophores of ARP116 followed a similar pattern to that in other A. bisporus strains. The developmental variant strain B430 was capable of initiating rudimentary primordia on axenic peat-based casing material but, similar to the observations of Elliott and Wood (1978) and Wannet et al (1999), the primordia were unable to grow beyond Stage 2 growth. Flegg and Wood (1985) found that light and electron microscope sections of primordia produced by $\mathrm{B} 430$ on axenic media showed them to be indistinguishable from normal primordia that were capable of further differentiation. As here, the rudimentary primordia consisted mainly of a disorientated mass of hyphae. The formation of normal primordia and the subsequent numbers of sporophores of B430 in nonaxenic culture were similar to those of other A. bisporus strains. This result contrasts with that of Elliott and Wood (1978), who were unable to demonstrate conclusively that B430 was capable of producing mature sporophores in vivo.

In flask culture, B430 primordia developed into mature sporophores using nonaxenic casing material but not with axenic casing material. This response indicates that the mechanism for producing rudimentary primordia in axenic casing material differs from that in nonaxenic casing material, where primordia capable of further differentiation are produced. The lack of sporophores of B430 in nonaxenic microcosms might have been due to the limited substrate weight (30 g compared with $400 \mathrm{~g}$ in flasks). Wood (1979) found that $A$. bitorquis strains produced hyphal aggregates on defined axenic media but, similar to B430, they were incapable of further differentiation. San Antonio and Peerally (1979) found no relationship between primordia formation of 22 strains of $A$. bitorquis on axenic media and sporophore production in culture on peat casing and compost. This report agrees with the results found here for primordia formation and sporophore production of $A$. bisporus strains on casing material and compost in nonaxenic culture. Rainey et al (1990) developed an in vitro Petri dish bioassay using A. bitorquis (strain W19) to determine the involvement of Pseudomonas spp. in stimulating initiation. However, subsequent tests (Fermor et al 2000) showed that the stimulatory response of W19 in the bioassay did not correspond with in vivo results obtained with $A$. bisporus in the microcosms used here.

This work supports the hypothesis (Flegg and Wood 1985) that inhibitors prevent initiation of primordia and that the putative inhibitors either can be metabolized by the casing microbiota $(P$. putida) or be adsorbed by certain casing materials. These putative inhibitors do not prevent the formation of rudimentary primordia in strain B430 but prevent the formation of primordia capable of differentiation. Further work is needed to determine whether the numbers of primordia and the proportion that develop into sporophores are related to the production of putative inhibitors by the mycelium of different $A$. bisporus strains, or their metabolism or adsorbtion by the casing layer.

\section{ACKNOWLEDGMENT}

This work was financed by the Department for Environment, Food and Rural Affairs.

\section{LITERATURE CITED}

Allen PG. 1975. Casing variables-plastic tunnels. Mushroom J 37:22-29.

Callac P, Billette C, Imbernon M, Kerrigan RW. 1993. Morphological, genetic, and interfertility analyses reveal a novel tetrasporic variety of Agaricus bisporus from the Sonoran Desert of California. Mycologia 85:835-851.

Eger G. 1961. Untersuchungen über die Function der Deckschicht bei der Früchtkörperbildung des Kulturchampignons, Psalliota bispora Lange. Archiv für Mikrobiologie 39:313-34.

. 1962. Untersuchungen über die Funktion der Deckschicht bei der Früchtkörperbildung des Kulturchampignons. Mushroom Sci 5:314-320.

Eitel W. 1966. Silicate science, IV Hydrothermal silicate systems. New York: Academic Press. 617 p. 
Elliott TJ. 1985. Spawn-making and spawns. In: Flegg PB, Spencer DM, Wood DA, eds. The biology of the cultivated mushroom. Chichester, UK: John Wiley \& Sons. p 131-139.

- Wood DA. 1978. A developmental variant of Agaricus bisporus. Trans British Mycological Soc 82:373-381.

Fermor T, Lincoln S, Noble R, Dobrovin-Pennington A. 2000. Microbiological properties of casing. In: van Griensven LJLD, ed. Science and cultivation of edible fungi. Rotterdam: Balkema. p 447-454.

Flegg PB. 1979. Effect of temperature on sporophore initiation and development in Agaricus bisporus. Mushroom Sci 10:595-602.

— Wood DA. 1985. Growth and fruiting. In: Flegg PB, Spencer DM, Wood DA, eds. The biology of the cultivated mushroom. Chichester, UK: John Wiley \& Sons. p 141-177.

Fletcher JT, White PF, Gaze RH. 1986. Mushrooms-pest and disease control. Newcastle upon Tyne, UK: Intercept. 156 p.

Fritsche G, Sonnenberg ASM. 1988. Mushroom strains. In: van Griensven LJLD, ed. The cultivation of mushrooms. Rustington, Sussex, UK: Darlington Mushroom Laboratories. p 101-123.

Grove JF. 1981. Volatile compounds from the mycelium of the mushroom Agaricus bisporus. Phytochem 20:20212022.

Hammond JBW, Nichols R. 1976. Carbohydrate metabolism in Agaricus bisporus (Lange) Sing.: changes in soluble carbohydrates during growth of mycelium and sporophore. J Gen Microbiol 93:309-320.

Hayes WA. 1978. Progress in the development of an alternative casing medium. Mushroom J 78:266-271.

— Nair NG. 1974. Effects of volatile metabolic by-products of mushroom mycelium on the ecology of the casing layer. Mushroom Sci 9(I):259-268.

— Randle PE, Last FT. 1969. The nature of the microbial stimulus affecting sporophore stimulation in Agaricus bisporus (Lange) Sing. Ann Appl Biol 64:177-187.

Lelliott RA, Stead DE. 1987. Methods for the diagnosis of bacterial diseases of plants. Methods in plant pathology. Vol. 2. Oxford, UK: Blackwell Scientific Publications. 216 p.

Long PE, Jacobs L. 1974. Aseptic fruiting of the cultivated mushroom Agaricus bisporus. Trans British Mycological Soc 63:99-107.

Miller N, Gillespie JB, Doyle OPE. 1995. The involvement of microbiological components of peat based casing material in fructification of Agaricus bisporus. In: Elliott TJ, ed. Science and cultivation of edible fungi. Rotterdam: Balkema. p 313-321.
Noble R, Gaze RH. 1995. Properties of casing peat types and additives and their influence on mushroom yield and quality. In: Elliott TJ, ed. Science and cultivation of edible fungi. Rotterdam: Balkema. p 305-312.

— - , Willoughby N. 1998. A high yielding substrate for mushroom experiments: formula 3. Mushroom J 587:27-28.

— Dobrovin-Pennington A, Evered CE, Mead A. 1999. Properties of peat-based casing soils and their influence on the water relations and growth of the mushroom (Agaricus bisporus). Plant and Soil 207:1-13.

Park JY, Agnihotri VP. 1969. Bacterial metabolites trigger sporophore formation in Agaricus bisporus. Nature (Lond.) 222:984.

Rainey PB. 1989. The involvement of Pseudomonas putida in sporophore initiation of the cultivated mushroom Agaricus bisporus. [PhD Dissertation]. Canterbury, New Zealand: University of Canterbury.

, Cole ALJ, Fermor TR, Wood DA. 1990. A model system for examining involvement of bacteria in sporophore initiation of Agaricus bisporus. Mycological Res 94:191-195.

San Antonio JP, Peerally A. 1979. Growth, primordia formation, and fruiting of twenty-two strains of Agaricus bitorquis. Mushroom Sci 10:587-594.

Stanier RY, Palleroni NJ, Doudoroff M. 1966. The aerobic Pseudomonads: a taxonomic study. J Gen Microbiol 43: 159-271.

Thompson R, Welham SJ. 2000. REML analysis of mixed models. In: Payne RW, ed. The guide to GenStat, Part 2: statistics. Oxford, UK: VSN International. p 413-503.

Tschierpe HJ. 1983. Environmental factors and mushroom strains. Mushroom J 132:417-29.

Umar MH, van Griensven LJLD. 1997. Morphologisch onderzoek: Levensfasen van een champignon. De Chamignoncultuur 41:47-50.

Visscher HR. 1979. Fructification of Agaricus bisporus (Lge.) Imb. in relation to the relevant microflora in the casing soil. Mushroom Sci 10(1):641-664.

Wannet WJB, Aben EMJ, van der Drift C, van Griensven LJLD, Vogels G, Op den Camp HJM. 1999. Trehalose phosphorylase activity and carbohydrate levels during axenic fruiting in three Agaricus bisporus strains. Current Microbiol 39:205-210.

Wood DA. 1976. Primordium formation in axenic cultures of Agaricus bisporus (Lange) Sing. J Gen Microbiol 95: 313-323.

-1979. Studies on primordium formation initiation in Agaricus bisporus and Agaricus bitorquis (syn) edulis. Mushroom Sci 10:565-586.

, Blight M. 1983. Sporophore initiation in axenic culture. Rep Glasshouse Crops Res Inst 1981:140. 